\title{
Modernizing medical careers: an open letter to Royal College Presidents
}

\author{
Jonathan Osborne
}

J R Soc Med 2006;99:56-57

I write to persuade you that the Royal Colleges' current policy of cooperating with the government and the postgraduate medical education and training board in implementing post-foundation medical training is not in the best long-term interests of either patients, future consultants, general practitioners or the Royal Colleges; all of whom will rely on a cadre of well-trained GPs and specialists to be the backbone of a service buffeted by incessant reform.

Led by the Royal Colleges, our current system of postgraduate training has evolved over centuries. Educational enthusiasts from every branch of British medicine developed a system of training and examination regarded by our overseas peers as an example to aspire to. Doctors came from all over the world to take college examinations and developed links with this country that persist to this day.

As a result of its evolutionary nature, there were inconsistencies between the training and assessment methods of different specialities and colleges. Nevertheless, standards of education and training have steadily improved to produce GPs and specialists whose abilities were respected world wide. Intercollegiate examinations and modern methods of formative and summative assessment were also making good progress in ironing out inconsistencies.

So why have we been seduced by government into embarking on wholesale chaotic change that is causing our most talented graduates to consider emigration and senior colleagues to worry about the standard of care they will receive in old age?

A number of influences have changed our training environment. Harmonization of training with Europe (Calmanization) ${ }^{1}$ appeared feasible, however the juggernaut of the European working time directive, ${ }^{2}$ applied with regulatory zeal by NHS human resources departments, has destabilized the traditional apprenticeship model of training.

The Royal Colleges' ability to reduce the productivity of the NHS in the interests of training has always been viewed

Chairman Welsh Joint Consultants Committee, Consultant ENT Surgeon, Glan Clwyd District General Hospital, Bodelwyddan LL18 5UJ, Wales, UK as an irritant by government. The creation of PMETB, under the control of the Secretary of State ${ }^{3}$ was deliberately designed to allow politicians to change the training of doctors at will. At a stroke the fox had entered the hen coop.

Where has this led us? Initially the Chief Medical Officer proposed a reform of the post qualification pre-registration year. ${ }^{4}$ The drudgery of house jobs was to be replaced with an enlightened curriculum providing a broad training whilst acquiring core competencies. This 2-year programme has been welcomed by the profession, but the upheaval of this alone will keep everyone fully occupied in the new training and assessment tasks necessary for its success.

The mischief really started when, under the Modernizing Medical Careers agenda, the Government produced a proposal to abolish senior house officers and create 'seamless' specialist training, ${ }^{5}$ churning out narrowly trained 'specialists' at the end of a further 4-5 years. Despite considerable misgivings, the colleges agreed to help to implement this, relinquishing their inspection and regulatory role to the Secretary of State assisted by postgraduate medical education and training board. Sweeping cuts to deanery budgets immediately followed.

What has gone wrong? It may be helpful to look at this in terms of:

1 The selection process with its manpower implications

2 The quality of the training itself

3 The likely output at completion of training.

\section{SELECTION AND MANPOWER}

Traditionally, there were a number of bottlenecks in medical career progression. Doctors spent time at the bottleneck grade widening their experience and either eventually succeeding by a combination of ability, determination and hard work, or finding something else more appropriate to their talents. Whilst this system had its faults, it produced doctors capable of dealing with the slings and arrows of consultant life or the uncertainties of general practice. Suddenly life has changed. Immediately after the second foundation year (F2), young doctors will have to make a near irreversible career decision in the face of 
frighteningly competitive odds. In surgery, it is likely there will be only 500 trainee posts for 3000 applicants. The present debacle over the availability of $\mathrm{F} 2$ posts will pale into insignificance compared to this cull. Already Australia and New Zealand are preparing to snap up newly qualified British doctors. In desperation the postgraduate medical education and training board is talking about a post-F2 nontraining year, exactly the situation the Chief Medical Officer wished to end when he described the 'lost tribe' of senior house officers.

Staff and associate specialist doctors also feature in this manpower equation. They have been shabbily treated. Encouraged to believe that they could convert to be accredited specialists under Article 14, they will find out that their assessment will include evidence of knowledge, i.e. examination success. However, in a Kafkaesque twist, they are prohibited from taking the Certificate of Completion of Training exit examination unless they occupy a training post, which will be almost impossible to obtain.

This is a manpower planning disaster from which neither government nor colleges emerge with distinction.

\section{THE TRAINING PROCESS}

What of the quality of specialist training itself? The period of post-foundation training is based on the American residency model, which aims to produce 'emergency safe' specialists. American residents, however, are not subject to the corrosive effects of the European working time directive and its shift culture. Chart rounds begin at $0700 \mathrm{~h}$ and residents are directly responsible for their patients' continuing care. In our brave new world, the trainee on shifts rarely sees his or her consultant to receive feedback. For general surgical trainees, 30000 hours of operative training have been reduced to 6000. For a general surgeon in a remote area, the prospect of being unprepared for an emergency laparotomy, with its myriad possibilities, is frightening.

Even at this late stage the curriculum and methods of trainee assessment are still 'under discussion'. It is unprecedented in peacetime for such a revolution in the training of doctors to be decided on the hoof.

\section{THE OUTPUT OF TRAINING}

What type of specialist we are likely to generate? A Certificate of Completion of Training holder will not be capable of undertaking the wide range of responsibilities shouldered by today's consultants. There is talk, sotto voce, of a specialist grade eventually progressing to consultant after further experience. The large increase in trainee numbers, combined with shrinkage in new consultant posts, appear to indicate this will happen by default, if not design. Cynics may welcome the return of the 'senior registrar', but it would be more honest to let our trainees know the likely outcome when they sign up to specialist training in the new, seamless model.

For all these reasons, I would suggest to you that further specialist training under the auspices of postgraduate medical education and training is now not fit for its purpose

Surely, we must concentrate on getting the F1 and F2 years right before instituting further reform which has not been properly thought out. If you, the presidents of the Royal Colleges, acted in concert and informed government that their proposals were unworkable and did not carry your confidence, they would be unable to proceed. Unkind members of our profession have alluded to the colleges as irrelevant drinking clubs, whose officers only seek the baubles of state, occasionally bestowed for keeping the profession quiet.

Please prove them wrong. At this precipitous moment the profession and patients look to you for leadership and unity in keeping with the proud traditions of the institutions you represent.

\section{REFERENCES}

1 Working Group on Specialist Medical Training. Hospital Doctors: Training For The Future. London: Department of Health, 1993

2 European Parliament Council. European Working Time Directive. Directive No. 93/104/EC, 1993 [http://europa.eu.int/scadplus/leg/en/cha/ c10405.htm]

3 Department of Health. The General and Specialist Medical Practice (Education, Training and Qualifications) Order. London: DoH, 2003

4 Sir Liam Donaldson, Chief Medical Officer for England. Unfinished Business - Proposals For Reform of The Senior House Officer Grade. September 2002 [www.dh.gov.uk/Consultations/ResponsesToConsultations/ ResponsesToConsultationsDocumentSummary/fs/en?CONTENT_ID= 4017024\&chk $=$ v/bRNy] 